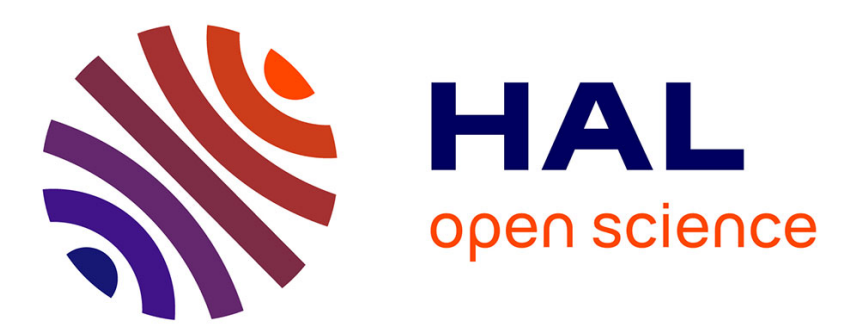

\title{
Detection of Broken Bars in Induction Motors Using an Extended Kalman Filter for Rotor Resistance Sensorless Estimation
}

Mohamed-Saïd Naït-Saïd, Mohamed Benbouzid, Abdelkrim Benchaib

\section{- To cite this version:}

Mohamed-Saïd Naït-Saïd, Mohamed Benbouzid, Abdelkrim Benchaib. Detection of Broken Bars in Induction Motors Using an Extended Kalman Filter for Rotor Resistance Sensorless Estimation. IEEE Transactions on Energy Conversion, 2000, 15 (1), pp.66-70. hal-01052443

\section{HAL Id: hal-01052443 https://hal.science/hal-01052443}

Submitted on 26 Jul 2014

HAL is a multi-disciplinary open access archive for the deposit and dissemination of scientific research documents, whether they are published or not. The documents may come from teaching and research institutions in France or abroad, or from public or private research centers.
L'archive ouverte pluridisciplinaire HAL, est destinée au dépôt et à la diffusion de documents scientifiques de niveau recherche, publiés ou non, émanant des établissements d'enseignement et de recherche français ou étrangers, des laboratoires publics ou privés. 


\title{
Detection of Broken Bars in Induction Motors Using an Extended Kalman Filter for Rotor Resistance Sensorless Estimation
}

\author{
M.S. Naït Saïd ${ }^{1, *}$, M.E.H. Benbouzid ${ }^{1}$, Senior Member, IEEE and A. Benchaib ${ }^{2}$, Member, IEEE $^{2}$ \\ ${ }^{1}$ University of Picardie "Jules Verne" \\ 7, Rue du Moulin Neuf, 80000 Amiens, France \\ *On Leave from the University of Batna, Algeria \\ ${ }^{2}$ Control Systems Research Group \\ Engineering Department, University of Leicester \\ University Road, Leicester LE1 7RH, UK
}

\begin{abstract}
This paper deals with the broken bars detection in induction motors. The hypothesis on which detection is based is that the apparent rotor resistance of an induction motor will increase when a rotor bar breaks. To detect broken bars, measurements of stator voltages and currents are processed by an Extended Kalman Filter for the speed and rotor resistance simultaneous estimation. In particular, rotor resistance is estimated and compared with its nominal value to detect broken bars. In the proposed extended Kalman Filter approach, the state covariance matrix is adequacy weighted leading to a better states estimation dynamic. Its main advantage is the correct rotor resistance estimation even for an unloaded induction motor. As part of this estimation process, it is necessary to compensate for the thermal variation in the rotor resistance. Computer simulations, carried out for a $4-\mathrm{kW}$ four-pole squirrel cage induction motor, provide an encouraging validation of the proposed sensorless broken bars detection technique.
\end{abstract}

Keywords: Induction motor, broken bars, rotor resistance, extended Kalman filter, simultaneous estimation.

\section{INTRODUCTION}

Induction motors are a critical component of many industrial processes and are frequently integrated in commercially available equipment and industrial processes. Motor driven often provide core capabilities essential to business success and to safety of equipment and personnel. There are many published techniques and many commercially available tools to monitor induction motors to insure high degree of reliability uptime. In spite of these tools, many companies are still faced with unexpected system failures and reduced motor lifetime. Environmental, duty, and installation issues may combine to accelerate motor failure far sooner than the designed motor lifetimes.

Critical induction motor applications are found in all industries and include all motor horsepowers.
It has been found that many of the commercial products to monitor induction motors are not cost-effective when deployed on typical low to medium horsepower induction motors. Advances in sensors, algorithms, and architectures should provide the necessary technologies for effective incipient failure detection [1-2].

In this context, a variety of sensors could be used to collect measurements from an induction motor for the purpose of failure monitoring. These sensors might measure stator voltages and currents, air-gap and external magnetic flux densities, rotor position and speed, output torque, internal and external temperature, and case vibrations, etc. In addition, a failure monitoring system could monitor a variety of motor failures. These failures might include conductor shorts and opens, bearing failures, cooling failures, etc. It is apparent then that a failure monitoring system should be capable of extracting, in a consistent manner, the evidence of many possible failures from measurements from many physically different sensors [3-6].

The actual trends for induction motors monitoring and diagnostics is achieved without thermal and mechanical sensors [7-8]. Therefore, based on the work initiated by Cho in [9], we have proposed a failure monitoring system combining the induction motor physical model with a minimum number of sensors.

To be specific about the proposed failure monitoring system, this paper deals with the broken bars detection in induction motors. The hypothesis on which detection is based is that the apparent rotor resistance of an induction motor will increase when a rotor bar breaks. To detect broken bars, measurements of stator voltages and currents are processed by an Extended Kalman Filter (EKF) for the speed and rotor resistance simultaneous estimation. In particular, rotor resistance is estimated and compared with its nominal value to detect broken bars. In the proposed EKF approach, the state covariance matrix is adequacy weighted leading to a better states estimation dynamic. Its main advantage is the correct rotor resistance estimation even for an unloaded induction motor. As part of this estimation process, it is necessary to compensate for the thermal variation in the rotor resistance. In 
fact, a difficulty with broken rotor bar detection is that a variation in the rotor temperature can cause significant variation in rotor resistance. In this case, the rotor resistance, so determined, must be referred and compared to the same temperature in normal operating point.

Several approaches have been proposed, in the available literature, for rotor resistance estimation [10-12]. The purpose of using and EKF approach is to improve the rotor resistance sensorless estimation using only stator voltages and currents measurements [13]. Moreover, the advantage of using stator currents as state variable is that they are directly measurable.

\section{THE INDUCTION MOTOR MODEL}

Induction motors can be described by fifth order nonlinear differential equations with four electrical variables (currents and fluxes), a mechanical variable (rotor speed), and two control variables (stator voltages). In $a-b$ axes fixed in the stator, one has

$$
\Psi_{0}=\left\{\begin{array}{l}
\dot{x}_{1}=-\gamma x_{1}+\frac{K_{L}}{T_{r}} x_{3}+n_{p} K_{L} x_{4} x_{5}+\alpha u_{a} \\
\dot{x}_{2}=-\gamma x_{2}+\frac{K_{L}}{T_{r}} x_{4}-n_{p} K_{L} x_{3} x_{5}+\alpha u_{b} \\
\dot{x}_{3}=\frac{L_{m}}{T_{r}} x_{1}-\frac{1}{T_{r}} x_{3}-n_{p} x_{4} x_{5} \\
\dot{x}_{4}=\frac{L_{m}}{T_{r}} x_{2}-\frac{1}{T_{r}} x_{4}+n_{p} x_{3} x_{5} \\
\dot{x}_{5}=n_{p} \frac{L_{m}}{J L_{r}}\left(x_{2} x_{3}-x_{1} x_{4}\right)-\frac{T_{L}}{J}-\frac{f_{f}}{J} x_{5}
\end{array},\right.
$$

where

$$
\gamma=\frac{R_{s}}{\sigma L_{s}}+\frac{R_{r} L_{m}^{2}}{\sigma L_{s} L_{r}^{2}}
$$$$
K_{L}=\frac{L_{m}}{\sigma L_{s} L_{r}},
$$$$
\alpha=\frac{1}{\sigma L_{s}}
$$$$
T_{r}=\frac{L_{r}}{R_{r}},
$$

$$
\sigma=1-\frac{L_{m}^{2}}{L_{s} L_{r}}
$$

$$
\begin{array}{lll}
a, b & = & \text { stator index } \\
u & = & \text { stator voltage } \\
\varphi & = & \text { stator flux } \\
i & = & \text { stator current }
\end{array}
$$

$$
\begin{array}{lll}
R_{s}\left(R_{r}\right) & = & \text { stator (rotor) resistance } \\
L_{s}\left(L_{r}\right) & = & \text { stator (rotor) inductance } \\
L_{m} & = & \text { mutual inductance } \\
\sigma & = & \text { total leakage coefficient } \\
n_{p} & = & \text { pole pair } \\
J & = & \text { rotor inertia } \\
f_{f} & = & \text { friction coefficient. }
\end{array}
$$

The stator voltages and the states are

$$
\left\{\begin{array}{l}
U^{T}=\left[\begin{array}{ll}
u_{a} & u_{b}
\end{array}\right] \\
X^{T}=\left[\begin{array}{lllll}
x_{1} & x_{2} & x_{3} & x_{4} & x_{5}
\end{array}\right]=\left[\begin{array}{llll}
i_{a} & i_{b} & \varphi_{a} & \varphi_{b}
\end{array}\right]
\end{array}\right]
$$

One can consider a nonlinear system described by the following equations.

$$
\begin{aligned}
& \dot{X}=f(X, U), \\
& Y=H(X),
\end{aligned}
$$

where $X(t)$ is a $n$-dimension state vector, $U(t)$ is a $m$ dimension control signal, and $Y(t)$ is a $p$-dimension measurement vector.

\section{THE EXTENDED KALMAN FILTER THEORY}

In this section, the extended Kalman filter theory will be briefly reviewed. The used filter is described by the following equations [13].

$\dot{X}(t)=f(X(t), u(t), t)+G(t) w(t)$,

$Y(t)=h(X(t), t)+v(t)$,

where

$G(t)=$ state noise matrix

$w(t)=$ state noise vector

$v(t)=$ measurement noise vector

The state prediction is

$\hat{X}\left(\frac{k+1}{k}\right)=\hat{X}\left(\frac{k}{k}\right)+\int_{t_{k}}^{t_{k+1}} f(X(t), u(t), t) d t$,

where $k$ is the sampling step. Using the medium value theorem, described by the following equation,

$\int_{t_{k}}^{t_{k+1}} f(t) d t=\left(t_{k+1}-t_{k}\right) f(t)=T_{s} f(t)$, 
equation (5) can be expressed as follows.

$$
\hat{X}\left(\frac{k+1}{k}\right)=\hat{X}\left(\frac{k}{k}\right)+T_{s} f(X),
$$

where $T_{s}$ is the sampling period.

The filter covariance matrix is given by

$$
P\left(\frac{k+1}{k}\right)=\Phi(k+1, k) P\left(\frac{k}{k}\right) \Phi(k+1, k)+Q(k),
$$

where the transition matrix is

$$
\Phi(k+1, k)=e^{T_{s} F(k)},
$$

with

$$
F=\left.\frac{\partial f}{\partial x}\right|_{x=\hat{x}}
$$

$\Phi(k+1, k)$ can be linearized by the Taylor development as

$$
\Phi(k+1, k) \approx 1+T_{s} F(k)
$$

The state noise variance matrix is expressed by the following equation.

$Q(k+1)=\int_{t_{k}}^{t_{k+1}} \Phi\left(t_{k+1}\right) G(\tau) Q(\tau) G^{T}(\tau) \Phi^{T}\left(t_{k+1}, \tau\right) d \tau$

The Kalman filter gain is

$$
K(k+1)=P\left(\frac{k+1}{k}\right) H^{T}(k+1) A(k+1)
$$

where

$$
\begin{aligned}
& A(k+1)=\frac{1}{H(k+1) P(k+1) H^{T}(k+1)+R(k+1)}, \\
& H(k+1)=\left.\frac{\partial h\{x(t), t\}}{\partial x}\right|_{x=\hat{x}\left(\frac{k+1}{k}\right)}, \\
& h\{x(t), t\}=\left[i_{a} i_{b}\right]^{T} .
\end{aligned}
$$

The state estimation is

$$
\hat{x}\left(\frac{k+1}{k+1}\right)=\hat{x}\left(\frac{k+1}{k}\right)+K(k+1) B(k+1),
$$

with

$$
B\left(\frac{k+1}{k+1}\right)=Y(k+1)-h\left(\frac{\hat{x}(k+1)}{k, k+1}\right) .
$$

The updated covariance matrix filter is then given by the following equation.

$$
P\left(\frac{k+1}{k+1}\right)=(I-K(k+1) H(k+1)) P\left(\frac{k+1}{k}\right) .
$$

\section{APPLICATION TO THE INDUCTION MOTOR}

The induction motor model described in section II is here used to apply the extended Kalman filter above reviewed. The state variables are selected as

$X^{T}=\left[\begin{array}{llllll}x_{1} & x_{2} & x_{3} & x_{4} & x_{5} & x_{6}\end{array}\right]=\left[\begin{array}{llllll}i_{a} & i_{b} & \varphi_{a} & \varphi_{b} & \omega & R_{r}\end{array}\right]$

The induction motor dynamic behavior is modeled as

$f^{T}=f^{T}(x(t), u(t), t)=\left[\begin{array}{llllll}f_{1} & f_{2} & f_{3} & f_{4} & f_{5} & f_{6}\end{array}\right]$,

$$
f=\left[\begin{array}{c}
\left(-\gamma_{1}-\gamma_{2} x_{6}\right) x_{1}+\frac{K_{L}}{L_{r}} x_{3} x_{6}+n_{p} x_{4} x_{5}+\frac{1}{\sigma L_{s}} u_{a} \\
\left(-\gamma_{1}-\gamma_{2} x_{6}\right) x_{2}-n_{p} K_{L} x_{3} x_{5}+\frac{K_{L}}{L_{r}} x_{6}+\frac{1}{\sigma L_{s}} u_{b} \\
\frac{L_{m}}{L_{r}} x_{1} x_{6}-\frac{1}{L_{r}} x_{4} x_{6}-n_{p} x_{3} x_{5} \\
\frac{L_{m}}{L_{r}} x_{2} x_{6}-\frac{1}{L_{r}} x_{4} x_{6}-n_{p} x_{3} x_{5} \\
n_{p} \frac{L_{m}}{J L_{r}}\left(x_{2} x_{3}-x_{1} x_{4}\right)-\frac{T_{L}}{J}-\frac{f_{f}}{J} x_{5} \\
0
\end{array}\right],
$$

where

$$
\begin{aligned}
& \gamma_{1}=\frac{R_{s}}{\sigma L_{s}}, \\
& \gamma_{2}=\frac{L_{m}^{2} R_{r}}{\sigma L_{s} L_{r}^{2}} .
\end{aligned}
$$

The measurement matrix is given by

$$
H=\left[\begin{array}{llllll}
1 & 0 & 0 & 0 & 0 & 0 \\
0 & 1 & 0 & 0 & 0 & 0
\end{array}\right]
$$

The Jacobean matrix, namely $F$, is deduced using (10). 


$$
F=\left[\begin{array}{cccccc}
-\gamma_{1}-\gamma_{2} x_{6} & 0 & x_{6} \frac{K_{L}}{L_{r}} & n_{p} K_{L} x_{5} & n_{p} K_{L} x_{4} & -\gamma_{2} x_{1}+\frac{K_{L}}{L_{r}} x_{3} \\
0 & -\gamma_{1}-\gamma_{2} x_{6} & -n_{p} K_{L} x_{5} & \frac{K_{L}}{L_{r}} x_{6} & n_{p} K_{L} x_{3} & -\gamma_{2} x_{2}+\frac{K_{L}}{L_{r}} x_{4} \\
\frac{L_{m}}{L_{r}} x_{6} & 0 & -\frac{x_{6}}{L_{r}} & -n_{p} x_{5} & -n_{p} x_{4} & \frac{L_{m}}{L_{r}} x_{1}-\frac{x_{3}}{L_{r}} \\
0 & \frac{L_{m}}{L_{r}} x_{6} & n_{p} x_{5} & -\frac{x_{6}}{L_{r}} & -n_{p} x_{3} & \frac{L_{m}}{L_{r}} x_{2}-\frac{x_{4}}{L_{r}} \\
-\frac{L_{m}}{J L_{r}} x_{4} x_{6} & n_{p} \frac{L_{m}}{J L_{r}} x_{4} & n_{p} \frac{L_{m}}{J L_{r}} x_{2} & -n_{p} \frac{L_{m}}{J L_{r}} x_{1} & -\frac{f_{f}}{J} & 0 \\
0 & 0 & 0 & 0 & 0 & 0
\end{array}\right] .
$$

\section{SIMULATION RESULTS}

The proposed estimation technique has been simulated on a 4-kW squirrel cage induction motor whose ratings are summarized in the appendix.

The validity of the proposed estimation technique is well verified by simulations as illustrated by Figs. 1 and 2. It should be noticed that these results have been obtained for an unloaded induction motor, which is generally more difficult to achieve by classical methods such as those based on the active and reactive power consumption analysis [14].

To be specific about broken bars monitoring, an abrupt stepwise on rotor resistance corresponds to a broken bar condition. This situation is also well identified by the proposed EKF technique as illustrated by Fig. 1. Moreover, broken bars affect not only the rotor resistance but also the magnetic flux leading to the decrease of the output torque capability (Fig. 3).

The rotor resistance is estimated with 1 and 3\%-error. Further, the spread of successive estimates given with or without broken bars is such that this increase is unambiguous, even considering manufacturing nonuniformities in the rotor. In fact, apart from the thermal compensation problem, Fig. 4 could, by itself, show that a broken bar is responsible for the increase in the rotor resistance because the proposed EKF technique provides estimates before and after bar breakage, which is not the case of the near least square error estimator proposed in [9]. The proposed estimator is quite sensitive even for no-load condition as also illustrated by Fig. 4. Moreover, the induction motor and the Kalman filter observer initial conditions are not identical but this situation does not affect the estimation process, which is not the case of the classical estimation methods particularly for unloaded induction motors [4].

One difficulty with the rotor resistance estimation and the broken bars detection is that a variation in the rotor temperature can cause a significant variation in $R_{r}$. A thermal variation in $R_{r}$ can be misinterpreted as, or mask the effect of, a broken bar [9]. Therefore, as part of the EKF estimation process, the thermal variation in the rotor resistance is compensated for by using the same approach developed in [7]. In fact, it is easy to monitor the rotor temperature from its resistance estimation and then its temperature dependence, which is given by
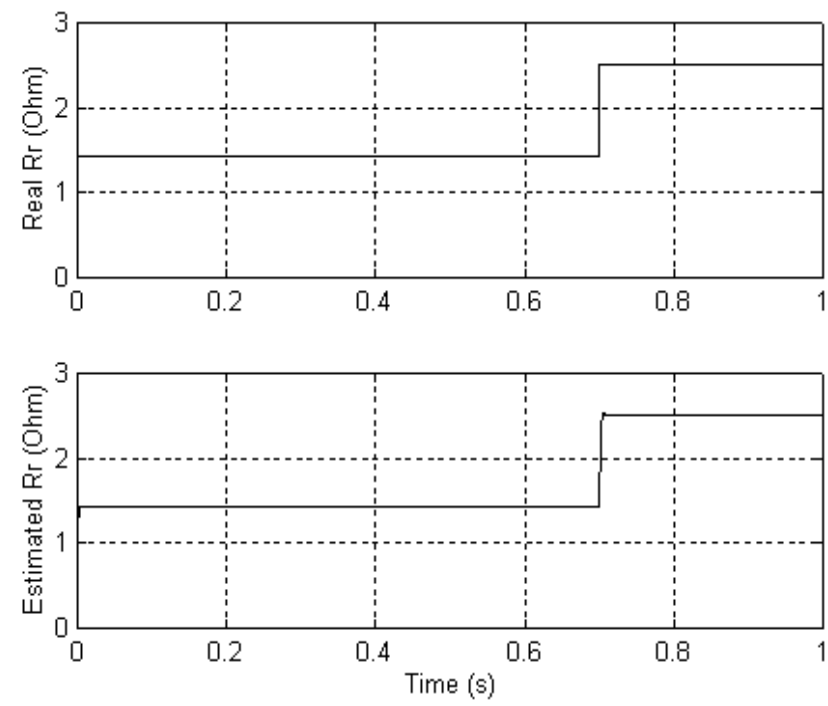

Fig. 1. Unloaded induction motor rotor resistance estimation with $74 \% R_{r}$ stepwise at $0.7 \mathrm{~s}$.
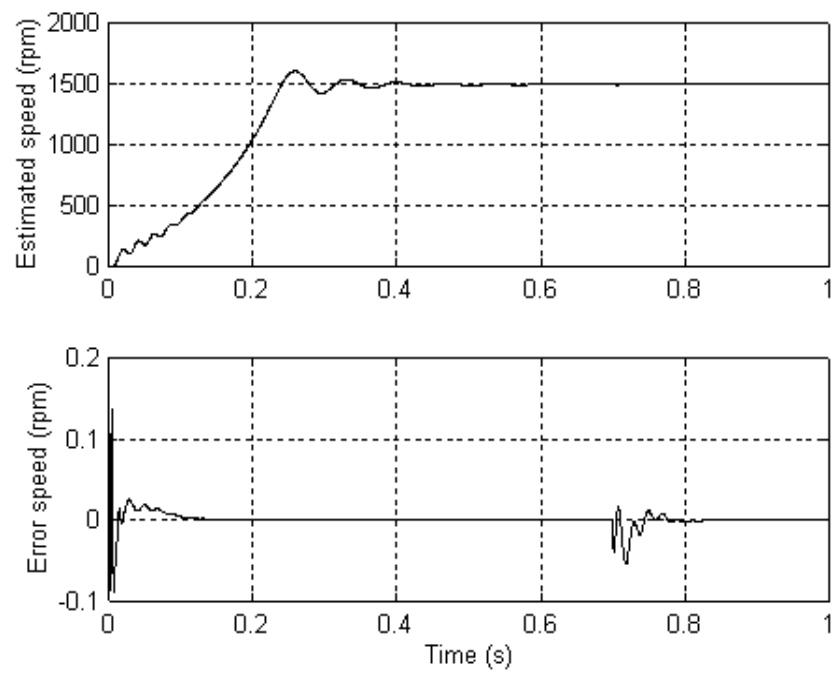

Fig. 2. Unloaded induction motor rotor speed estimation with $74 \% R_{r}$ stepwise at $0.7 \mathrm{~s}$ 

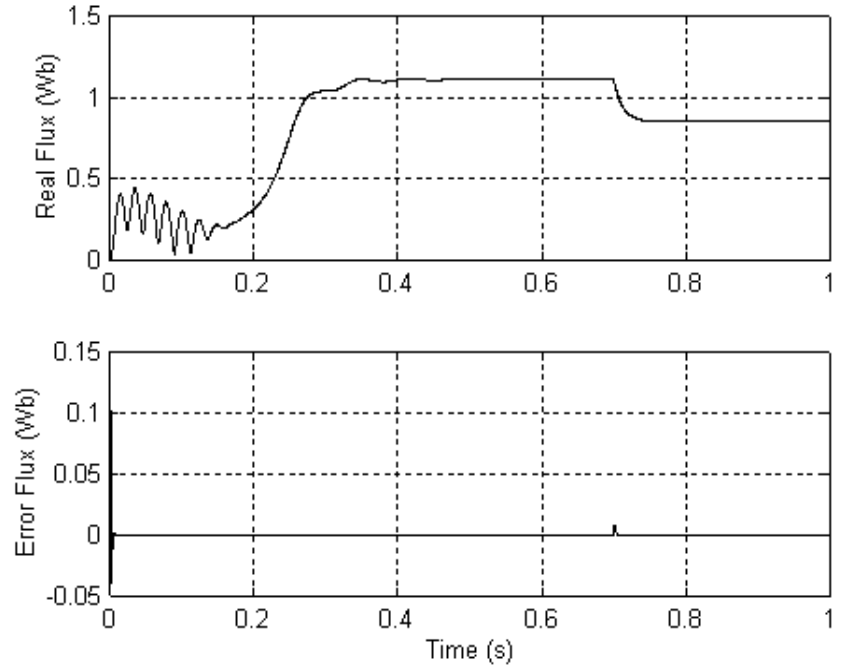

Fig. 3. Unloaded induction motor rotor flux estimation with rotor resistance $74 \%$ stepwise at $0.7 \mathrm{~s}$.
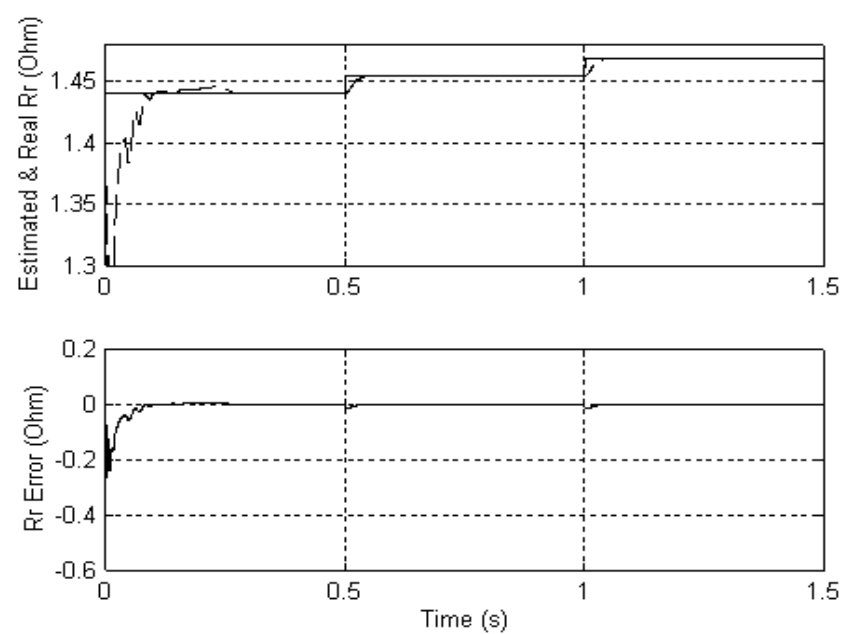

Fig. 4. Unloaded induction motor rotor flux estimation with $1 \%$ (one broken bar) to $2 \%$ (two broken bars) rotor resistance increase.

$R=R_{0}(1+\alpha \Delta T)$,

where

$$
\begin{array}{lll}
R_{0} & = & \text { resistance at reference temperature } T_{0}=25^{\circ} \mathrm{C} \\
\alpha & = & \text { resistance temperature coefficient } \\
\Delta T & = & \text { temperature increase }
\end{array}
$$

Equation (23) provides a means for thermally compensating $R_{r}$. Assuming that this compensation works as planned, variations in the thermally compensated rotor resistance estimation can be attributed to broken bars alone.

For illustration, the Kalman filter capability to track exponential profile, modeling the rotor resistance thermal effect, has been tested. This is shown by Fig. 5. One can notice that the estimation accuracy is quite satisfactory for monitoring purposes.
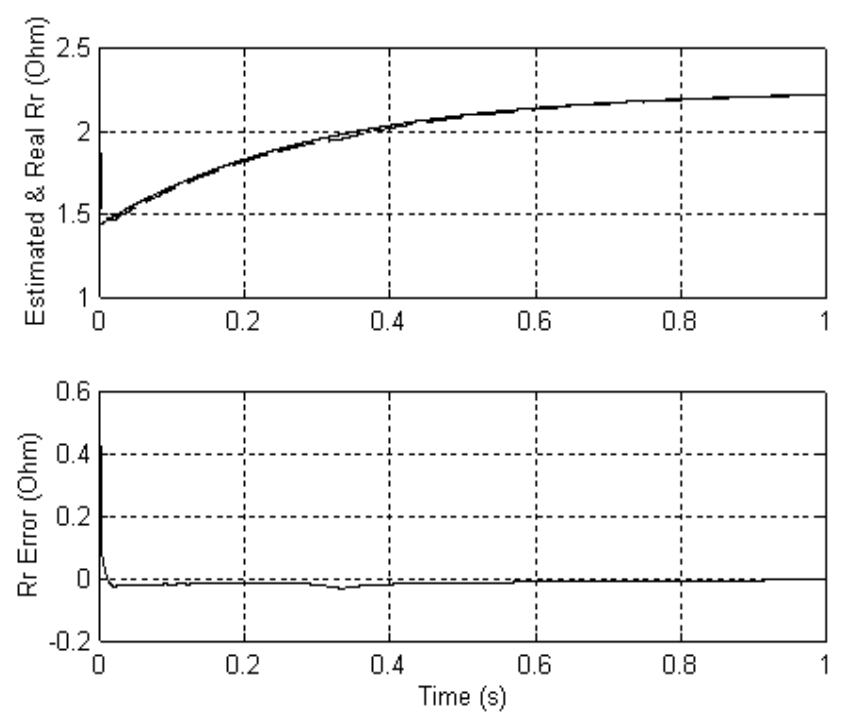

Fig. 5. Induction motor rotor resistance estimation

with a rotor resistance exponential profile variation, for a load of $10 \mathrm{~N} \cdot \mathrm{m}$.

\section{CONCLUSION}

This paper was devoted to the problem of broken bars detection in induction motors. The hypothesis on which detection is based is that the apparent rotor resistance of an induction motor will increase when a rotor bar breaks. To detect broken bars, measurements of stator voltages and currents are processed by an Extended Kalman Filter for the speed and rotor resistance simultaneous estimation. In particular, rotor resistance is estimated and compared with its nominal value to detect broken bars. In the proposed extended Kalman Filter approach, the state covariance matrix is adequacy weighted leading to a better states estimation dynamic. Its main advantage is the correct rotor resistance estimation even for an unloaded induction motor. Computer simulations, carried out for a $4-\mathrm{kW}$ four-pole squirrel cage induction motor, provide an encouraging validation of the proposed broken bars monitoring technique.

APPENDIX

RATED DATA OF THE SIMULATED INDUCTION MOTOR

\begin{tabular}{llll}
\hline \multirow{2}{*}{ Rated values } & Power & \multicolumn{1}{l}{4} & $\mathrm{~kW}$ \\
& Frequency & 50 & $\mathrm{~Hz}$ \\
& Voltage $(\Delta / \mathrm{Y})$ & $220 / 380$ & $\mathrm{~V}$ \\
& Current $(\Delta / \mathrm{Y})$ & $15 / 8.6$ & $\mathrm{~A}$ \\
& Speed & 1440 & $\mathrm{rpm}$ \\
& Pole pair $\left(n_{p}\right)$ & 2 & \\
Rated parameters & $R_{s}$ & 1.150 & $\Omega$ \\
& $R_{r}$ & 1.100 & $\Omega$ \\
& $l$ & 0.013 & $\mathrm{H}$ \\
Constants & $M$ & 0.203 & $\mathrm{H}$ \\
& $\alpha$ & 0.004 & $1 /{ }^{\circ} \mathrm{C}$ \\
& $J$ & 0.042 & $\mathrm{~kg} \cdot \mathrm{m}^{2}$ \\
& $f_{f}$ & 0.032 & $\mathrm{IS}$ \\
\hline
\end{tabular}




\section{REFERENCES}

[1] D.J.T. Siyambalapitiya and P.G. McLaren, "Reliability improvement and economic benefits of on-line monitoring system for large induction machines," IEEE Trans. Industry Applications, vol. 26, n 6 , JulyAugust 1990, pp. 1018-1025.

[2] F.M. Discenzo et al., "Motor diagnostics: Technological drivers leading to 21st century predictive diagnostics," Proceedings of the 1997 International Conference on Maintenance and Reliability, Knoxville, Tennessee (USA), vol. 1, May 1997, pp. 30.01-30.12.

[3] A.H. Bonnett and G.C. Soukup, "Cause and analysis of stator and rotor failures in three-phase squirrel-cage induction motors, "IEEE Trans. Industry Applications, vol. 28, n4, July-Aug. 1992, pp. 921-937.

[4] P. Vas, Parameter Estimation, Condition Monitoring, and Diagnosis of Electrical Machines, Oxford, Clarendon Press, 1993.

[5] G.B. Kliman and J. Stein, "Methods of motor current signature analysis," Electric Machines \& Power Systems, vol. 20, n5, September 1992, pp. 463-474

[6] M.E.H. Benbouzid and R. Beguenane, "Induction motor diagnostics via stator current monitoring," Proceedings of the 1997 International Conference on Maintenance and Reliability, Knoxville, Tennessee (USA), vol. 1, May 1997, pp. 36.01-36.10.

[7] R. Beguenane and M.E.H. Benbouzid, "Induction motors thermal monitoring by means of rotor resistance identification" IEEE Trans. Energy Conversion, Ref. PE-I155-EC-0-2-1998.

[8] M.E.H. Benbouzid, M. Vieira and C. Theys, " Induction motors faults detection and localization using stator current advanced signal processing techniques," IEEE Trans. Power Electronics, vol. 14, n¹, January 1999, pp. 14-22.

[9] K.R. Cho, J.H. Lang and S.D. Umans, "Detection of broken rotor bars in induction motors using state and parameter estimation," IEEE Trans. Industry Applications, vol. 28, n³, May-June 1992, pp. 702-709.

[10]C.C. Chan and H. Wang, "An effective method for rotor resistance identification for high-performance induction motor vector control," IEEE Trans. Industrial Electronics, vol. 37, n6, December 1990, pp. 477-482.

[11]R. Krishnan and A.S. Bharadwaj, "A review of parameter sensitivity and adaptation indirect vector controlled induction motor drive systems," IEEE Trans. Power Electronics, vol. 6, n4 , October 1991, pp. 693-703.

[12]S.I. Moon and A. Keyhani, "Estimation of induction machine parameters from standstill time domain data," IEEE Trans. Industry Applications, vol. 30, n6, November-December 1994, pp. 1609-1615.

[13]L.C. Zai, C.L. Demarco and T.A. Lipo, "An extended Kalman filter approach to rotor time constant measurement in PWM induction motor drives," IEEE Trans. Industry Applications, vol. 28, n¹, JanuaryFebruary 1992, pp. 96-104.

[14]E.C. Anderson and T. Vetter, "Parameter identification and on-line rotor temperature monitoring of ac squirrel cage motors," Proceedings of the 1988 International Conference on Electrical Machines, Pisa (Italy), September 1988, pp. 251-256.

\section{BIOGRAPHIES}

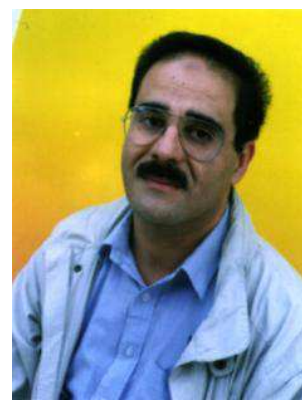

Mohamed Saïd NAIT SAID was born in Batna, Algeria, on September 15, 1958. He received the B.Sc. degree in Electrical Engineering, in 1983, from the National Polytechnic Institute of Algiers, Algeria and the M.Sc. degree in Electrical and Computer Engineering, in 1992, from the Electrical Engineering Institute of Constantine University, Algeria. After graduation, he joined the University of Batna, Algeria, where he is a Teaching Assistant at the Electrical Engineering Institute. M.S. Naït Saïd is actually working towards a Ph.D. thesis on the control of induction motors in the University of Picardie "Jules Verne" at Amiens, France.

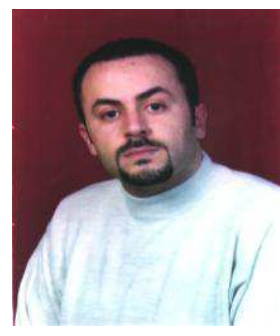

Mohamed EI Hachemi BENBOUZID (S'92M'94-SM'98) was born in Batna, Algeria, in 1968. He received the B.Sc. degree in Electrical Engineering, in 1990, from the Electrical Engineering Institute of Batna University, Algeria; the M.Sc. and Ph.D. degrees both in Electrical and Computer Engineering, from the National Polytechnic Institute of Grenoble, France, in 1991 and 1994 respectively. After graduation, he joined the University of Picardie "Jules Verne", France, where he is an Associate Professor of Electrical and Computer Engineering at the Professional Institute of Amiens. His current research interests include electric machines and drives, computational of electromagnetics, and electromechanical actuation, as well as techniques for energy savings. Dr. Benbouzid is a member of the IEEE Industrial Electronics, Industry Applications, Power Engineering, and Magnetics Societies, and the French Electrotechnical and Electronic Association (SEE). He is particularly active in the IEEE Power Engineering Society Working Group on Motor Maintenance and Failure Analysis of the Induction Machinery Subcommittee of the Electric Machines Committee. (phone +33 $32228276 \quad 80, \quad$ Fax $+33 \quad 3 \quad 22 \quad 82 \quad 78$ 22, e-mail m.benbouzid@ieee.org)

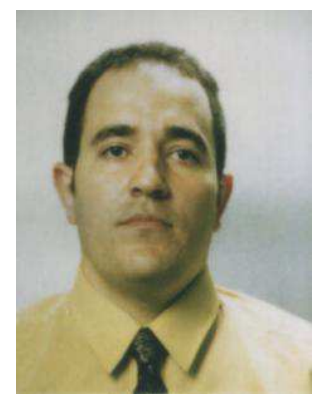

Abdelkrim BENCHAIB (M'97) was born in Maghnia, Algeria, on December 1969. He received the B.Sc. degree on Electrical Engineering, in 1993, from the Science and Technology University of Oran, Algeria and the M.Sc. degree in Automatic and Manufacturing Systems, in 1995, from the Science and Technology University of Lille, France. He joined the Automatic Systems Laboratory of the University of Picardie "Jules Verne" at Amiens, France, in November 1995. Since January 1998, he is with the Control System Research Group, Engineering Department, University of Leicester, UK. His areas of research interests are nonlinear control, sliding mode control, nonlinear observers, and electrical drives. 